\title{
Evidence that the CAG repeat in the androgen receptor gene is associated with the age-related decline in serum androgen levels in men
}

\author{
K Krithivas, S M Yurgalevitch ${ }^{1}$, B A Mohr ${ }^{1}$, C J Wilcox, S J Batter, \\ M Brown, C Longcope ${ }^{2}$, J B McKinlay ${ }^{1}$ and P W Kantoff
}

The Lank Center for Genitourinary Oncology, Department of Adult Oncology, Dana-Farber Cancer Institute, Harvard Medical School, 44 Binney Street,
Boston, Massachusetts 02115, USA
${ }^{1}$ New England Research Institutes, 9 Galen Street, Watertown, Massachusetts 02172, USA
${ }^{2}$ Department of Obstetrics and Gynecology, University of Massachusetts Medical Center, 55 Lake Avenue North, Worcester, Massachusetts 01655, USA
(Requests for offprints should be addressed to P W Kantoff)

\begin{abstract}
In men over 30 years old, serum levels of testosterone $(T)$ decrease with age. A shorter polymorphic CAG repeat length in exon 1 of the androgen receptor (AR) gene is associated with higher transcription activation by the AR. We determined the number of CAG repeats for 882 men aged between 40 and 70 years from the Massachusetts Male Aging Study (MMAS). MMAS is a population-based random sample survey of men for whom baseline (19871989 , mean age $53 \pm 8$ years) and follow-up (1995-1997, mean age $61 \pm 8$ years) serum hormone levels were available. Multiple linear regression was used to determine if CAG repeat length would be predictive of hormone levels at follow-up. Hormone levels measured included T,
\end{abstract}

free $\mathrm{T}$, albumin-bound $\mathrm{T}$, dihydrotestosterone (DHT), sex hormone-binding globulin (SHBG) and luteinizing hormone (LH). The CAG repeat length was significantly associated with T $(P=0 \cdot 041)$, albumin-bound T $(P=0 \cdot 025)$ and free $\mathrm{T}(P=0 \cdot 003)$ when controlled for age, baseline hormone levels and anthropometrics. Follow-up levels of T decreased by $0 \cdot 74 \% \pm 0 \cdot 36$ per CAG repeat decrement. Likewise, the percentages of free and albumin-bound $\mathrm{T}$ decreased by $0.93 \% \pm 0.31$ and $0.71 \% \pm 0.32$ per CAG repeat decrement respectively. These results suggest that androgen levels may be modulated by AR genotype.

Journal of Endocrinology (1999) 162, 137-142

\section{Introduction}

Several studies have shown convincingly that androgen levels decrease with advancing age (Deslypere \& Vermeulen 1984, Gray et al. 1991, Simon et al. 1992). The largest of these, the Massachusetts Male Aging Study (MMAS), analyzed 415 healthy men and 1294 men with one or more ailments between the ages of 40 and 70 years (Gray et al. 1991). This cross-sectional study showed decreases in albumin-bound testosterone $(\mathrm{T})$ and free $\mathrm{T}$ of $1 \cdot 0$ and $1 \cdot 2 \%$ per year respectively. Sex hormone-binding globulin (SHBG) increased $1.2 \%$ per year. These results amount to an overall decline in total $\mathrm{T}$ of $0 \cdot 4 \%$ per year. Age-related declines in serum androgen levels are attributed to reduced functioning at all three levels of the hypothalamic-pituitarytesticular axis as well as an increase in SHBG levels (Vermeulen 1991, Swerdloff \& Wang 1993, Gooren 1996).

$\mathrm{T}$ negatively modulates hypothalamic peptidergic neurons, presumably by way of androgen receptors (ARs) located within adjacent neurons (Huang \& Harlan 1993). The binding of $\mathrm{T}$ to the $\mathrm{AR}$ allows the complex to interact with specific androgen responsive elements and initiate transcription of target genes (Lubahn et al. 1989, Simental et al. 1991, Santen 1995). Two studies have shown that a polymorphic CAG repeat residing in exon 1 of the AR gene modulates AR transcription activation (Chamberlain et al. 1994, Kazemi-Esfarjani et al. 1995). The CAG repeat, encoding for a polyglutamine tract in the AR, ranges normally from about 6 to 39 repeats with an average of between 20 and 22 (Edwards et al. 1992, Giovannucci et al. 1997). Age-related declines in androgen levels due to AR status have not been investigated. In this study, we explore whether serum androgen levels are modulated by AR activity based upon the length of its polyglutamine tract in a cohort of randomly selected men. We provide evidence that AR status, by way of this functional polymorphism, may affect age-related androgen decline.

\section{Subjects and Methods}

\section{Population}

The MMAS is among the largest population-based longitudinal databases on male endocrine function, health 
status, sexual functioning, and psychosocial correlates. The baseline sample was assembled between 1987 and 1989. The follow-up study (1995-1997) was designed to examine hormone profiles in the same MMAS subjects approximately 8 years after the baseline study.

The study population consists of 1709 men (aged 40-70 years old at baseline) from 11 randomly selected cities and towns in the greater Boston, MA, USA area. The list of men was generated by randomly selecting names from computerized city and town street lists. In-home interviews were conducted within $2 \mathrm{~h}$ of waking. Information on current medication use, alcohol/ tobacco intake, physical activity, sociodemographic variables and physical measurements was collected. Physical measurements included height, weight, and waist and hip circumferences. Two non-fasting blood samples were drawn 30 min apart within $2 \mathrm{~h}$ of waking. Blood samples were centrifuged and stored at $-80{ }^{\circ} \mathrm{C}$ until analysis. Equal aliquots from the samples were pooled for analysis. T (Judd et al. 1974), free T (Longcope et al. 1987), albuminbound $\mathrm{T}$ (Hammond et al. 1982), dihydrotestosterone (DHT) (Longcope et al. 1986), SHBG (Longcope et al. 1987) and luteinizing hormone (LH) (Ciba Corning kit, Medfield, MA, USA) were measured using the referenced techniques. The assay used did not change over the study period. The interassay coefficients of variation were less than $13 \%$, and the intra-assay coefficients of variation were less than $11 \%$ for all determinations.

Of the 1709 men from the original sample, 1156 men completed follow-up. The remaining 553 men were either deceased (186), lost to follow-up (75), refused (259), too ill to participate (28) or out of the country (5). Of the 1156 men interviewed at follow-up, hormone and CAG data were obtained from 1031 men who consented and were not taking anticoagulants. Excluded from the analysis in this paper were 56 men with prostate cancer and 93 men who had other non-cutaneous malignancies or were being treated for enlarged prostates. This resulted in a total sample size of 882 men.

\section{Androgen receptor $C A G$ repeat length analysis}

Only one copy of the AR gene exists in men since it is located on the X-chromosome. The polymorphic CAG repeat region resides on exon 1 of the AR gene. A system to rapidly and accurately determine the CAG repeat length status in a large number of samples was developed. Buffy coats were isolated from whole blood. Genomic DNA was extracted from $100 \mu$ buffy coat utilizing the Qiagen 96 Spin Kit (Chatsworth, CA, USA) which allows for high-throughput processing. The CAG repeat region of the AR gene was amplified via the PCR utilizing 6-Fam and Hex fluorescent labeled sense primers (GibcoBRL, Grand Island, NY, USA). The sense and antisense primer sequences were TCCAGAATCTGTTCCAG AGCGTGC and GCTGTGAAGGTTGCTGTTCCT
CAT respectively. The $22 \mu \mathrm{l}$ reaction volume consisted of $10 \mathrm{mM}$ Tris- $\mathrm{HCl}, 50 \mathrm{mM} \mathrm{KCl}, 1.5 \mathrm{mM} \mathrm{MgCl}_{2}, 10 \mathrm{nmol}$ each dNTP, 17 pmol each primer, and 1.5 units Taq polymerase (Perkin Elmer, Norwalk, CT, USA). After an initial denaturing step of $94^{\circ} \mathrm{C}$ for $2 \mathrm{~min}$, the 35-cycle PCR consisted of $94 \mathrm{EC}$ for $30 \mathrm{~s}, 60{ }^{\circ} \mathrm{C}$ for $30 \mathrm{~s}$, and $72{ }^{\circ} \mathrm{C}$ for $30 \mathrm{~s}$. The final extension step was $72^{\circ} \mathrm{C}$ for $8 \mathrm{~min}$. Each sample generated a single PCR fragment whose size was dependent on the number of CAG repeats. For rapid and accurate assessment of fragment length, the PCR products were run on a $6 \%$ denaturing polyacrylamide gel and detected by automated fluorescence detection (Applied BioSystems, Foster City, CA, USA, Model 377) in the Dana-Farber Cancer Institute Molecular Biology Core Facility. The data were analyzed using the GeneScan $2 \cdot 0$ software (Applied BioSystems). The software generates a standard curve utilizing a fluorescent labeled molecular weight standard (Rox 2500) run in each lane of the polyacrylamide gel. PCR fragments of unknown length are accurately sized based upon the generated standard curve. Resolution of one base pair using this system was confirmed by dye terminator DNA sequencing. The assay was conducted by laboratory personnel blinded to sample hormone level status.

\section{Statistical analysis}

To determine whether there were significant changes in hormone levels from baseline to follow-up, Wilcoxon signed-rank tests were performed. Due to the positive skew of some of the hormone distributions, the values were $\log$ transformed before being used in further analyses. Correlations between CAG repeat length, age, hormone levels and anthropometric measurements were calculated using Pearson correlation coefficients. The anthropometric measurements included height, weight, waist and hip circumferences, waist to hip ratio (WHR), and body mass index (BMI).

The age trends for the hormones were calculated by subtracting baseline log hormone levels from the log of follow-up levels for each subject and then dividing the result by the amount of time between the two measurements. This yields the rate of change per year for each individual on the $\log$ scale. The sample mean and the standard error of the rates were then calculated. Percentage change was estimated and transformed back to the original scale by substituting the sample mean in for $\mathrm{b}$ in the formula: percent change per year $=100 \% \star\left(e^{b}-1\right)$. The standard error of the percent change was computed by substituting the standard error in for $\mathrm{b}$ in the formula. Note that this method of calculating age-dependent hormone level trends is different from the one used in an earlier paper from the MMAS (Gray et al. 1991). This paper was a cross-sectional analysis of hormone levels in this population. Since that study was conducted, a repeat 
Table 1 Characteristics of 882 MMAS subjects. Age at baseline was recorded between 1987 and 1989. All other measurements were conducted at follow-up (1995-1997)

Mean \pm standard deviation

Age at baseline (years)

Age at follow-up (years)

Number of CAG repeats

Waist to hip ratio

Race
White
Black
Other

determination was made allowing for a longitudinal analysis of hormone levels.

Multiple linear regression was used to determine if associations exist between CAG repeat length and hormone levels, with each hormone considered in a separate model. Follow-up hormone levels were treated as the dependent variable and CAG as the independent variable while age, baseline hormone and WHR were controlled for. The percent change in hormone per CAG repeat was computed by using the formula for percent change mentioned above, but instead substituting the regression coefficient for $\mathrm{CAG}$ in for $\mathrm{b}$.

The data in Fig. 2 were obtained as follows. The baseline median value for $\mathrm{T}$ was plotted at baseline. The follow-up values of $\mathrm{T}$ were calculated by substituting baseline median $\mathrm{T}$ and mean age and WHR into the regression equation. Then different values of CAG were substituted to obtained predicted values of $\mathrm{T}$.

\section{Results}

Table 1 shows the characteristics of the 882 MMAS subjects in the sample. The mean age ( \pm standard deviation) at baseline (1987-1989) and follow-up (1995-1997) was $53 \pm 8$ years and $61 \pm 8$ years. Baseline age ranged from 40 to 70 . The CAG allele frequency distribution is displayed in Fig. 1. The range of AR CAG repeats was 8-37 with a mean of $22 \pm 3$.

Table 2 presents medians and age trends for the hormones from this study. The differences between median levels at baseline and follow-up were statistically significant for all the hormones (Wilcoxon signed-rank test, $P<0 \cdot 0001)$. Levels of T decreased by $1 \cdot 46 \%$ per year. Percent free $\mathrm{T}$ and albumin-bound $\mathrm{T}$ decreased by 1.38 and $0 \cdot 87 \%$ per year respectively. Simultaneously, there was a rise in DHT, SHGB, and LH levels of 3·40, 1.11 and $1.72 \%$ per year respectively.

Correlations between CAG repeat length and hormone levels ranged from -0.04 to 0.10 and were not statistically significant except for those between CAG and follow-up $\mathrm{T}(\mathrm{r}=0 \cdot 08, P=0 \cdot 024)$. Weak but statistically significant correlation was found between WHR and hormone levels with coefficients ranging from -0.23 to $0 \cdot 08$ (data not shown).

In multiple linear regression analyses controlling for age, baseline hormone levels, and WHR, the AR CAG repeat length was significantly associated with follow-up $T$ $(P=0.041)$, free $\mathrm{T}(P=0.003)$, and albumin-bound $\mathrm{T}$ $(P=0.025)$ but not with DHT, SHBG or LH. FSA and estrone. Table 3 shows the rise in follow-up $T$ levels, percentage of free $\mathrm{T}$ and percentage of albumin-bound $\mathrm{T}$ per three CAG repeats. Figure 2 illustrates what the regression models imply about the age-related decline in androgen levels. T levels were plotted against time for four subjects with identical baseline $\mathrm{T}$, age and WHR but different $\mathrm{CAG}$ repeat lengths. The baseline $\mathrm{T}$ is the median baseline $\mathrm{T}$ form (Table 2). The follow-up levels are predicted values from the regression analysis. This figure shows that subjects with lower CAG will have lower levels of $\mathrm{T}$ at follow-up. A lower follow-up level represents a greater decline in $\mathrm{T}$.

\section{Discussion}

There is a decline in serum $\mathrm{T}$, free- $\mathrm{T}$, and albumin-bound $\mathrm{T}$ levels with advancing age in men. Since serum androgen levels are regulated via the hypothalamicpituitary-testicular axis, age-related declines in androgen levels are probably a consequence of impaired functioning at all three levels. Although the declines may be relatively small in absolute terms, they may be clinically significant since aging men sustain reductions in muscle mass, bone mass, libido and have an increase in visceral fat.

In this report, we postulate an additional level of control for age-associated androgen declines. Since hypothalamic ARs mediate the suppressive effects of androgens, variations in AR activity may modulate the strength of androgen negative feedback and thereby influence serum androgen levels. Variability in AR activity occurs as a consequence of a trinucleotide repeat sequence, CAG, in exon 1 of the AR gene. Several findings show that the CAG repeat length modulates AR transcription activation: 1) Transfection assays demonstrate that ARs with shorter polyglutamine repeat lengths have greater transcription activation function (Chamberlain et al. 1994, KazemiEsfarjani et al. 1995); 2) Expansion to greater than 40 repeats causes $\mathrm{X}$-linked recessive bulbospinal neuronopathy (X-BSNP; Kennedy's disease) and leads to clinical androgen insensitivity (LaSpada et al. 1991, Igarashi et al. 1992). Patients with X-BSNP fail to suppress T levels after administration of synthetic androgen fluoxymesterone (Sobue et al. 1994); 3) Individuals with shorter polyglutamine repeats, resulting in more active ARs, have a higher risk for prostate cancer, a disease which is in part 


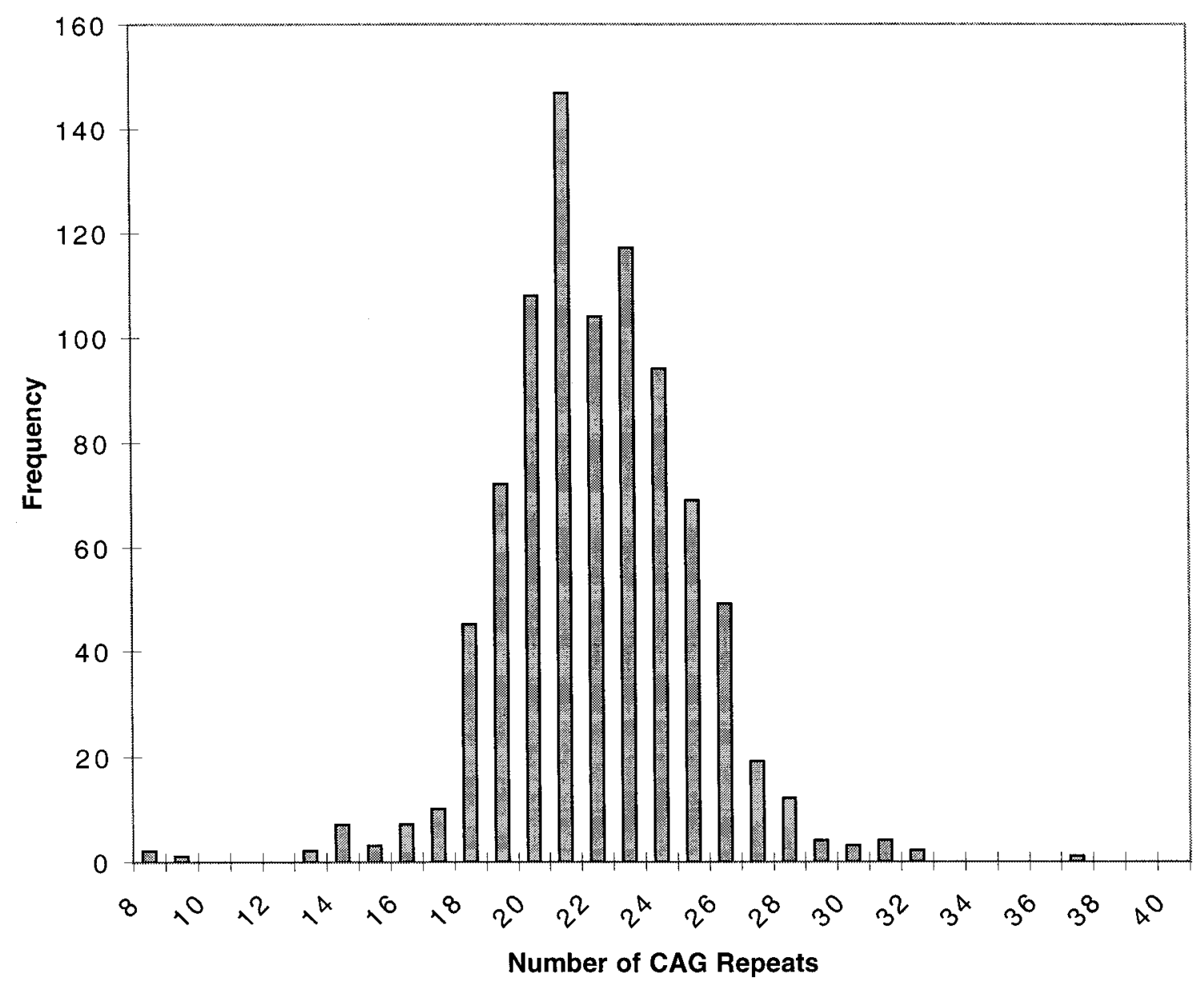

Figure 1 AR CAG repeat allele distribution of 882 MMAS subjects.

androgen mediated (Giovannucci et al. 1997). Therefore, individuals with fewer CAG repeats in their AR gene could have an increased response to androgen negative feedback and in turn a greater age-associated androgen decline.

In this study we found that an individual with a shorter CAG repeat will have lower T, $\%$ free $\mathrm{T}$ and $\%$ albuminbound $\mathrm{T}$ at follow-up, representing faster rates of decline compared with an individual with a longer repeat. Specifically, an individual has a $0 \cdot 74 \%$ lower $\mathrm{T}$ level, a $0.93 \%$ lower percentage of free $\mathrm{T}$, and a $0.71 \%$ lower percentage of albumin-bound $\mathrm{T}$ after an 8-year period relative to an individual with one greater repeat and identical baseline hormone levels, age and WHR. Examination of subjects at baseline and follow-up alone failed to reveal any strong correlation between AR CAG repeat length and hormone levels at each time point (data not shown). This is possibly due to the wide variability in serum hormone levels in the population. The longitudinal analysis presented in this report overcame subject to subject variability and allowed for relatively subtle age trends within individuals to be followed.

Despite the finding that serum androgen levels are associated with AR CAG repeat lengths, no association was found between CAG repeats and LH levels, a major determinant of serum androgen level. One reason may be the variability of LH levels due to its pulsatile manner of secretion. The pulse frequency is approximately once every $2 \mathrm{~h}$ with amplitude ranges from 20 to $400 \%$ (Santen 1995). During the half-hour sampling period, it may not be possible to select a time point on the $\mathrm{LH}$ pulse curve to obtain standardized LH levels between individuals nor on the same individual at baseline and follow-up. Another reason for dissociation of CAG repeats and LH levels may be that immunoreactive LH (iLH) was measured, whereas bioactive $\mathrm{LH}(\mathrm{bLH})$ may be a better indicator of $\mathrm{LH}$ levels (Gooren 1996). LH measurements based upon immunoassays may be inappropriately elevated due to the 
Table 2 Median hormone levels at baseline (1987-1989) and follow-up (1995-1997) and percent hormone level changes per year for 882 MMAS subjects from the present study

\begin{tabular}{|c|c|c|c|}
\hline & \multicolumn{2}{|c|}{$\begin{array}{l}\text { Median } \\
\left(25^{\text {th }} \text { Percentile, } 75^{\text {th }} \text { Percentile }\right)\end{array}$} & \multirow[b]{2}{*}{$\%$ Change per year \pm S.E. } \\
\hline & Baseline & Follow-up & \\
\hline $\mathrm{T}(\mathrm{ng} / \mathrm{ml})$ & $\begin{array}{l}5 \cdot 09 \\
(4 \cdot 07,6 \cdot 28)\end{array}$ & $\begin{array}{l}4 \cdot 36^{*} \\
(3 \cdot 53,5 \cdot 43)\end{array}$ & $-1 \cdot 46 \pm 0 \cdot 14$ \\
\hline Free T (\%) & $\begin{array}{l}1.93 \\
(1.58,2.27)\end{array}$ & $\begin{array}{l}1 \cdot 67^{\star} \\
(1 \cdot 38,2 \cdot 03)\end{array}$ & $-1 \cdot 38 \pm 0 \cdot 14$ \\
\hline Albumin-bound T (\%) & $\begin{array}{l}35 \cdot 12 \\
(28 \cdot 38,42 \cdot 55)\end{array}$ & $\begin{array}{l}32 \cdot 97^{\star} \\
(26 \cdot 48,39 \cdot 26)\end{array}$ & $-0 \cdot 87 \pm 0 \cdot 16$ \\
\hline $\mathrm{DHT}(\mathrm{ng} / \mathrm{ml})$ & $\begin{array}{l}0 \cdot 23 \\
(0 \cdot 16,0 \cdot 33)\end{array}$ & $\begin{array}{l}0 \cdot 31^{*} \\
(0 \cdot 21,0 \cdot 44)\end{array}$ & $+3 \cdot 40 \pm 0 \cdot 27$ \\
\hline SHBG (nM) & $\begin{array}{l}28 \cdot 00 \\
(22 \cdot 00,38 \cdot 00)\end{array}$ & $\begin{array}{l}32 \cdot 06^{*} \\
(23 \cdot 10,44 \cdot 33)\end{array}$ & $+1 \cdot 11 \pm 0 \cdot 16$ \\
\hline $\mathrm{LH}(\mathrm{IU} / \mathrm{L})$ & $\begin{array}{l}4 \cdot 00 \\
(3 \cdot 00,6 \cdot 00)\end{array}$ & $\begin{array}{l}4 \cdot 80^{*} \\
(3 \cdot 40,6 \cdot 70)\end{array}$ & $+1 \cdot 72 \pm 0 \cdot 19$ \\
\hline
\end{tabular}

${ }^{*} P<0 \cdot 0001$, Wilcoxon signed-rank test (baseline median=follow-up median).

decreased clearance rate of inactive LH glycoforms with aging.

In two previous studies (Zumoff et al. 1982a,b, Deslypere \& Vermeulen 1984), DHT was found not to decline with age although $\mathrm{T}$ did. These studies were cross-sectional in design, and in the present report the analysis was longitudinal. In a previous study involving the present cohort (Zumoff et al. 1982a,b) which was also cross-sectional, DHT was age invariant, so that the finding of an increase in DHT levels may be a reflection of the study design and the difference in a cross-sectional versus longitudinal study.

The data presented in this report support the finding of Sobue et al. (1994) who reported that patients with X-linked recessive BSNP (Kennedy's disease), characterized by AR CAG repeats of 40 or more, did not suppress $\mathrm{LH}$ and $\mathrm{T}$ levels after administration of the synthetic androgen fluoxymesterone. The data in this report further biologically link CAG repeat length in the AR gene with androgen/AR signaling. The findings of Sobue et al.

Table 3 Percent change in follow-up hormones per three CAG repeats for 882 MMAS subjects. Results are adjusted for age, baseline hormone level and WHR

\% Change per three CAG repeats (95\% confidence intervals)

$\begin{array}{lr}\text { T }(\mathrm{ng} / \mathrm{ml}) & 2 \cdot 2(0 \cdot 01,4 \cdot 4) \\ \text { Free T (\%) } & 2 \cdot 8(1 \cdot 0,4 \cdot 7) \\ \text { Albumin-bound T (\%) } & 2 \cdot 1(0 \cdot 3,4 \cdot 1) \\ \text { DHT }(\mathrm{ng} / \mathrm{ml}) & -0 \cdot 9(-4 \cdot 4,2 \cdot 7) \\ \text { SHBG (nM) } & -1 \cdot 2(-3 \cdot 6,1 \cdot 3) \\ \text { LH }(\mathrm{IU} / \mathrm{l}) & 0 \cdot 3(-2 \cdot 5,3 \cdot 2)\end{array}$

*Three $\mathrm{CAG}$ repeats $=$ one standard deviation.
(1994) coupled with these data suggest that longer AR CAG repeats decrease AR activity in the hypothalamus resulting in decreased negative feedback and increased serum androgen levels.

In summary, this population-based study of men followed longitudinally suggests a biologic relationship between CAG repeat length, AR function and serum androgen levels. It further suggests that a comprehensive clinical assessment of androgenicity should include not only serum androgen levels but perhaps AR function including AR CAG repeat length.

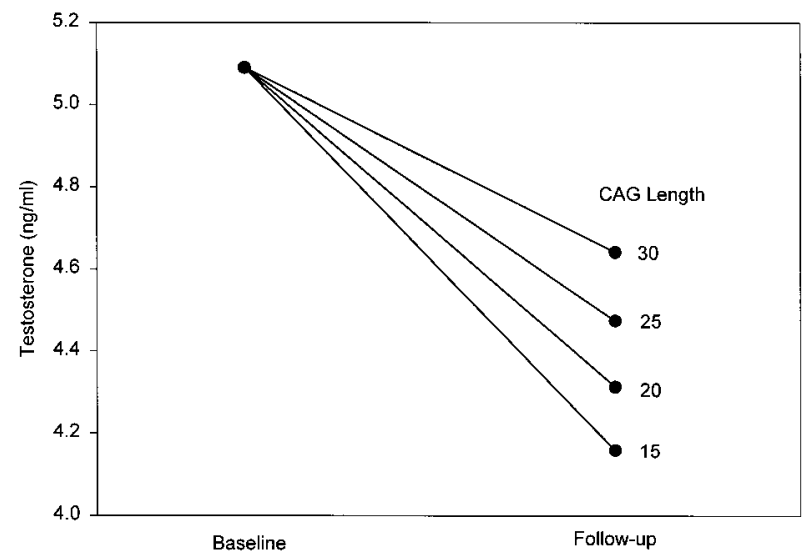

Figure 2 Graph of $T$ versus time for four subjects with identical baseline $T$, age and WHR but different CAG repeat lengths. The median value for T $(5.09 \mathrm{ng} / \mathrm{ml})$ was plotted at baseline. Follow-up levels were predicted values from a multiple linear regression model controlling for age, WHR and baseline T levels. This figure illustrates that men with shorter CAG repeat lengths will have lower $\mathrm{T}$ at follow-up, which represents a faster rate of decline. 


\section{Acknowledgements}

This work was supported by The National Institutes of Health-NIA, NCI, NIDDK DK 44995-03, DK51345-03, and CaPCURE.

\section{References}

Chamberlain NL, Driver ED \& Miesfeld RL 1994 The length and location of CAG trinucleotide repeats in the androgen receptor $\mathrm{N}$-terminal domain affect transactivation function. Nucleic Acids Research 15 3181-3186.

Deslypere JP \& Vermeulen A 1984 Leydig cell function in normal men: effect of age, life style, residence, diet and activity. Journal of Clinical Endocrinology and Metabolism 59 955-962.

Edwards A, Hammond HA, Lin J, Caskey CT \& Chakraborty R 1992 Genetic variation at five trimeric and tetrameric tandem repeat loci in four human population groups. Genomics 12 241-253.

Giovannucci E, Stampfer MJ, Krithivas K, Brown M, Dahl D, Brufsky A, Talcott J, Hennekens CH \& Kantoff PW 1997 The CAG repeat within the androgen receptor gene and its relationship to prostate cancer. Proceedings of the National Academy of Sciences of the USA 94 3320-3323.

Gooren LJG 1996 The age-related decline of androgen levels in men: clinically significant? British Journal of Urology 78 763-768.

Gray A, Feldman HA, McKinlay JB \& Longcope C 1991 Age, disease, and changing sex hormones levels in middle-aged men: results of the Massachusetts Male Aging Study. Journal of Clinical Endocrinology and Metabolism 73 1016-1025.

Hammond GL, Lahteenmaki PLA, Lahteenmaki P \& Luukkainen T 1982 Distribution and percentages of nonprotein bound contraceptive steroids in human serum. Journal of Steroid Biochemistry 17 375-380.

Huang X \& Harlan RE 1993 Absence of androgen receptors in LHRH immunoreactive neurons. Brain Research 624 309-311.

Igarashi S, Tanno Y, Onodera O, Yamazaki M, Sato S, Ishikawa A, Miyatani N, Nagashima M, Ishikawa Y, Sahashi K, Ibi T, Miyatake T \& Tsuji S 1992 Strong correlation between the number of CAG repeats in androgen receptor genes and the clinical onset of features of spinal and bulbar muscular atrophy. Neurology 42 2300-2302.

Judd HL, Judd GE, Lucas WE \& Yen SSC 1974 Endocrine function of the postmenopausal ovary: concentration of androgens and estrogens in ovarian and peripheral vein blood. Journal of Clinical Endocrinology and Metabolism 39 1020-1024.

Kazemi-Esfarjani P, Trifiro MA \& Pinsky L 1995 Evidence for a repressive function of the long polyglutamine tract in the human androgen receptor: possible pathogenic relevance for the $(\mathrm{CAG})_{\mathrm{n}}$-expanded neuronopathies. Human Molecular Genetics 4 523-527.

LaSpada AR, Wilson EM, Lubahn DB, Harding AE \& Fishbeck KH 1991 Androgen receptor gene mutations in X-linked spinal and bulbar muscular atrophy. Nature 352 77-79.

Longcope C, Franz C, Morello C, Baker R \& Johnston CC 1986 Steroid and gonadotropin levels in women during the perimenopausal years. Maturitas 8 189-196.

Longcope C, Hui SL \& Johnston CC 1987 Free estradiol, free testosterone, and sex hormone-binding globulin in perimenopausal women. Journal of Clinical Endocrinology and Metabolism 64 513-518.

Lubahn DB, Tan J-A, Quarmby VE, Sar M, Joseph DR, French FS \& Wilson EM 1989 Structural analysis of the human and rat androgen receptors and expression in male reproductive tract tissues. Annals of the New York Academy of Sciences 564 48-56.

Santen R 1995 The testis. In Endocrinology and Metabolism, edn 3, pp 885-911; 1819-1821. Eds P Felig, JD Baxter \& LA Frohman. New York: McGraw-Hill, Inc.

Simental JA, Sar M, Lane MV, French FS \& Wilson EM 1991 Transcriptional activation and nuclear targeting signals of the human androgen receptor. Journal of Biological Chemistry 266 510-518.

Simon D, Preziosi P, Barrett-Connor E, Roger M, Saint-Paul M, Nahoul K \& Papoz L 1992 The influence of aging on plasma sex hormones in men: the Telecom study. American Journal of Epidemiology 135 783-791.

Sobue G, Doyu M, Morishima T, Mukai E, Yasuda T, Kachi T \& Mitsuma T 1994 Aberrant androgen action and increased size of tandem CAG repeat in androgen receptor gene in X-linked recessive bulbospinal neuronopathy. Journal of Neurological Sciences 121 167-171.

Swerdloff RS \& Wang C 1993 Androgen deficiency and aging in men. Western Journal of Medicine 159 579-585.

Vermeulen A 1991 Androgens in the aging male. Journal of Clinical Endocrinology and Metabolism 73 221-224.

Zumoff B, Strain GW, Kream J, O'Connor J, Rosenfeld RS, Levin J \& Fukushima DK 1982a Age variation of the 24-h mean plasma concentration of androgens, estrogens, and gonadotropins in normal adult men. Journal of Clinical Endocrinology and Metabolism $\mathbf{5 4}$ 534-538.

Zumoff B, Levin J, Strain GW, Rosenfeld RS, O'Connor J, Freed SZ, Kream J, Whitmore WS, Fukushima DK \& Hellman L $1982 b$ Abnormal levels of plasma hormones in men with prostate cancer: evidence toward a 'two-disease' theory. Prostate 3 579-588.

Received 29 May 1998

Revised manuscript received 11 January 1999

Accepted 1 March 1999 